\title{
EXPANDABLE MULTITERMINAL DC SYSTEMS BASED ON VOLTAGE DROOP
}

\author{
B.K. Johnson \\ Member \\ University of Idaho
}

\author{
R.H. Lasseter \\ Fellow
}

University of Wisconsin-Madison

F.L. Alvarado

Senior Member
Abstract

This paper introduces a decentralized control scheme for the parallel connection of multiple rectifiers feeding a dc network with numerous inverters. The coordination of multiple HVdc systems without explicit communication is accomplished by the use of dc-side voltages as a "droop" mechanism. The dc side voltage serves the role of frequency in an ordinary ac system. The approach is most suitable to superconducting dc systems and to dc systems that span small distances and where voltage is relatively uniform throughout the $\mathrm{dc}$ system. This paper presents the concept in the context of a high capacity superconducting $10 \mathrm{KV}$ urban infeed. Keywords: Superconducting power transmission, Power distribution, High power converters.

\section{INTRODUCTION}

Multiterminal HVdc (MTdc) systems use extensions of the techniques from two terminal systems. These techniques assume several control modes (loops) at each converter, with logic which decides between modes. Typical operating modes found in two terminal systems include control of $\mathrm{dc}$ voltage, $\mathrm{dc}$ current, extinction angle, firing angle and a voltage dependent current limit. The transition and set point of each control mode is tightly coordinated with the other converter and its control action. As these concepts are extended to multiterminal systems, the complexity becomes excessive. A five terminal system with two control modes per terminal has thirty two possible states of control. For three control modes per terminal, there are over 200 operating states possible. If we add contingencies for loss of one terminal, additional complexity is added to the design of the controls.

It is difficult to build multiterminal systems with

93 WM 070-3 PWRD A paper recommended and approved by the IEEE Transmission and Distribution Committee of the IEEE Power Engineering Society for presentation at the IEEE/PES 1993 Winter Meeting, Columbus, OH, January 31 - February 5, 1993. Manuscript submitted September 1, 1992; made available for printing December 14, 1992 . more than five terminals. 'The most complex systems in operation today use only three terminals. This is in conflict with the desire to have small "off-the-shelf" converters which could be added to a system as load growth requires. This could involve hundreds of small converters at greatly reduced cost per $\mathrm{KW}$. To design such systems the tight coordination between controls on different converters must be broken without reliance on fast communications. Instead of using methods developed for point-to-point $\mathrm{HVdc}$ control, the paradigms of the ac system are more useful. Traditional ac systems have used to advantage the natural variability of demand with frequency and voltage. The supply system is designed, by means of the notion of droop, to permit the balancing of demand with supply at all times. Surely, control center regulation and economic dispatch are important to the efficient operation of the system, but the system is inherently stable without reliance on communications $[1,2,3]$. This paper introduces a similar notion for certain multi-terminal dc systems: those that are tightly coupled electrically. The ideal situation is a lossless dc system, whether meshed or not. The primary emphasis of this paper is on the use of a superconducting low voltage dc system. The concept is simple: all of the terminals in a superconducting $d c$ transmission system reach equal steady-state voltages since there is no resistive voltage drop in a superconductor. Changes in dc voltage propagate throughout the $\mathrm{dc}$ system, and can be used for control in a fashion similar to the use of change in frequency on ac systems.

One advantage of this approach is its expandability: inverters can be added at arbitrary locations. The concept appears most suitable initially for use in high capacity urban infeeds where modularity is important.

\section{LVDC TRANSMISSION SYSTEMS}

The elimination of resistive losses in superconducting cables allows the use of low voltage/high current transmission. A transmission system can operate at a single voltage level from generator to distribution. This eliminates or reduces the need for transformers. Low voltage levels reduce dielectric losses and insulation costs [4]. All superconductors, particularly high temperature superconductors, experience ac losses. This suggests that de transmission may be advantageous. Ad- 
vantages of dc must be balanced against an additional cost for power conversion and the potential complexity of multi-converter systems. Superconducting dc transmission require smaller cables and less refrigeration as a result of lower losses. A dc system experiences losses within converters and harmonic losses within cables.

The evolution of dc systems has been hampered by the difficulties associated with multi-converter configurations. Initial application of superconducting low voltage dc (LVdc) systems will probably begin with point to point dc systems. Using the ideas in this paper, these systems can be expanded by adding parallel taps for additional rectifier and inverter terminals. The low voltage level allows for simple modular converters. The voltage level can be on the order of 10 $\mathrm{kV}$, eliminating the need for series connection of devices within converters. Simple six-pulse modules could be connected in parallel to achieve a desired current rating. This suggests a system with a large number of "off the shelf" mass produced converter modules. A typical LVdc transmission system could consist of numerous rectifiers feeding hundreds of inverter terminals. The LVdc system could continue to grow through the addition of terminals and lines, forming a dc mesh for increased transmission reliability. For more details on the concept of superconducting meshed systems, refer to $[6]$ :

\section{MTDC SYSTEMS}

Traditional control schemes for multiterminal HVdc (MTdc) systems are extensions of the point to point HVdc system control concepts, which are based on the notion of control modes [7]. The basic control scheme regulates the mesh voltage level at one converter terminal, and operates the remaining terminals in a current regulation mode. The terminal regulating voltage is unable to control its local current. Its current is determined by the current demands of other converter terminals. This is undesirable for an inverter that is scheduled to supply a mostly passive load system. Therefore, voltage control during normal operation is limited to rectifiers. The current limits of the voltage regulating converter can create problems during transients. Many implementations of this basic scheme depend on the presence of a central controller to balance current orders between converters. This requires fast communication to coordinate currents during a disturbance $[8,9,10,11]$. A scheme with the ability to coordinate control without fast communication was proposed by Lasseter, Krüeger, and Povh [12]. Schemes for controlling a mesh connected multiterminal HVdc systems run into difficulty when one of the converters reaches a current limit. The voltage regulating converter changes to current regulation mode. One of the other converters must then regulate dc voltage. The scheme described in $[12]$ is able to change modes through an intricate design of the control characteristics.

This approach to control results in a complicated and carefully customized overall control scheme for a large system. It becomes increasingly difficult to determine which converter should assume voltage regulation following mode changes as system size increases.

A desirable multi-converter dc system could have multiple dispersed rectifiers feeding an arbitrary number of inverters. The control scheme for such a system must be able to handle converter limits without fast communication or intricate mode switching. The control scheme must be general rather than tailored to a specific system layout. This will make the system simpler to expand.

Regulating the mesh voltage at a single terminal is undesirable. A more effective scheme is to operate all of the rectifier terminals in a joint voltage regulation mode. The overall control system must be designed to respond properly to faults and disturbances. The key is for the system to be able to maintain stable operation in the face of disturbances without reliance on communications among converters, even it this operating point is suboptimal. The system can then be moved to a better operating point with communications. The control system must be designed to provide damping to the $\mathrm{dc}$ system, since there is little inherent damping provided by the cables.

Superconducting cables change several key system characteristics, and have a major impact on control options. There is no longer a current dependent dc voltage drop. Voltage regulation sets a single voltage level for all the terminals. Also, cables have a self-protective nature: large overcurrents cause the superconductive cables to quench, so they no longer operate in a zero resistance, superconducting state.

\section{VOLTAGE DROOP CONTROL}

A distributed voltage regulation scheme must maintain consistent sharing of current between the rectifiers. A useful analogy is the use of frequency droop to provide natural regulation characteristics for all generators in the system. A sloping power versus frequency natural regulation characteristic is used for each generator to regulate the initial distribution of real power among generators. This scheme uses a change in frequency as a signal for the control system to meet changes in power demand. Natural regulation requires no communications, and it is followed by load-frequency control which refers to automatic means of regulation responsive to frequency, tie flows and other system variables [2].

A voltage droop scheme can be implemented for ordinary dc systems, but it is easier to implement for a superconducting system. Each of the nodes on the dc system reaches the same steady-state voltage level. Thus, it is possible to use the voltage on the dc system as a signal. This is the key concept in this paper. 
The analogy to generators is not perfect. The control of ac voltage provided by generators has no counterpart in the regulation of the $\mathrm{dc}$ mesh, since reactive power is not a valid concept for the dc network. Voltage replaces frequency as a system-wide signal, and there is no second quantity that needs regulation.

\section{Built-in rectifier droop}

Each line commutated rectifier bridge has a current dependent voltage drop due to commutation overlap. This can be modeled as a resistance in steady-state converter models [5]. Rectifier operation in a constant firing angle mode can be modeled as a voltage source connected to the mesh through a resistance. Thus, line commutated rectifiers have a "built-in" droop. Changes in the current drawn off of the rectifiers alter the voltage drop across the resistance. The change in current divides between several rectifier terminals according to their equivalent resistances via current division. The system will settle into a new steady-state at a different voltage level following a change in total current.

The system response to changes in current demand is similar to that with frequency droop on ac systems. This can be demonstrated for a system with three parallel connected rectifier bridges. Figure 1 shows a simplified model for three rectifiers feeding a dc system represented as a variable current load. Each of the three rectifiers features identical droop resistances. The distribution of a change in current between the rectifiers is based on a simple resistive current divider. This is demonstrated in equations 1 and 2. This representation is sufficient for observing steady state operating points. All of the nodes reach equal steady state operating voltages. This is not adequate for representing the dynamics of the changes because the dc system isn't included. The RL time constant between the slope of the droop characteristic, and the inductance in the path between a given rectifier and the inverter that changed its current demand affects the response.

$$
\begin{aligned}
\Delta I_{\text {tot }} & =\Delta I_{1}+\Delta I_{2}+\Delta I_{3} \\
& =\frac{\Delta V}{R_{1}\left\|R_{2}\right\| R_{3}} \\
\Delta I_{1} & =\Delta I_{\text {tot }} * \frac{R_{2} \| R_{3}}{R_{1}+R_{2} \| R_{3}} \\
\Delta I_{2} & =\Delta I_{\text {tot }} * \frac{R_{1} \| R_{3}}{R_{2}+R_{1} \| R_{3}} \\
\Delta I_{3} & =\Delta I_{\text {tot }} * \frac{R_{1} \| R_{2}}{R_{3}+R_{1} \| R_{2}}
\end{aligned}
$$

The system begins in an initial state with each rectifier supplying $7000 \mathrm{~A}$ to the mesh at $7500 \mathrm{~V}$, shown as operating point A of Figure 2. The total current drawn by the dc system is then decreased by $3 k A$. The system operating voltage increases as the current is decreases,

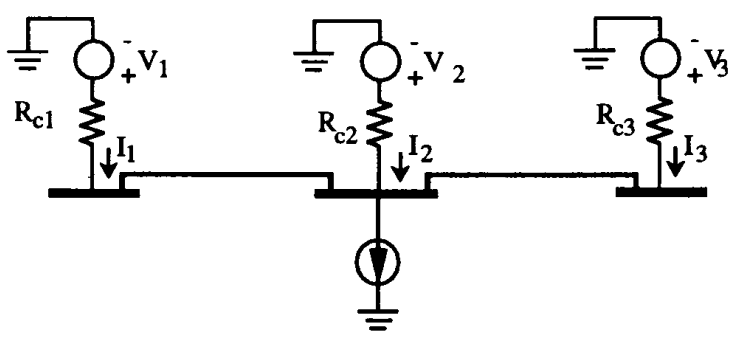

Fig. 1: Simplified Equivalent of dc System Fed by Three Rectifiers

shown as point $B$ on the figure, where each of the rectifiers supplies $6 \boldsymbol{k} A$.

Operating point $\mathrm{C}$ on Figure 2 shows a case where rectifier 3 shuts down. The other two rectifiers pick up the load supplied by that rectifier, increasing their currents to $9 k A$. A well designed system will have sufficient excess capacity in the rectifier terminals to operate with any one of the terminals out of service.

\section{Dynamics of droop control}

The built-in droop for a large rectifier is quite small. It takes a large change in current to change the mesh voltage level significantly. This is desirable for normal operation since it will result in a relatively constant $\mathrm{dc}$ voltage level. This makes it simpler to regulate power at the inverters. However, it also means that large changes in current bring the generators to their MVA limits without a significant change in the mesh voltage. Large changes in the dc voltage can be used to trigger load shedding at the inverters. In such a case a steeper slope on the droop characteristic would be desirable. This would allow more ability for the inverters to help the system reach a stable point.

The built in droop on each rectifier terminal has some disadvantages. The relative slopes of individual droop characteristics are fixed by the physical parameters of the generator or transformer connected to each rectifier. This may result in a case where a small rectifier will have flatter characteristics than a large rectifier, and will pick up a greater share of the current swings. This is desirable only if large rectifier terminals are treated as the "base loaded rectifiers."

The slope of the droop of each of the rectifier terminals can be adjusted dynamically. The firing angle of the rectifier can be varied to give the effect of an additional resistance, $K_{\alpha}$, appearing as:

$$
V_{d c}=V_{d o} \cos \left(\alpha_{\min }\right)-K_{\alpha} * I_{d c}-R_{c} * I_{d c}
$$

This provides the ability compute the trajectory of $\alpha$ to give a desired droop. The new firing angle is calculated through the series of steps shown in equations 4 and 5 , where $V_{\text {des }}$ is the desired dc voltage for a given 


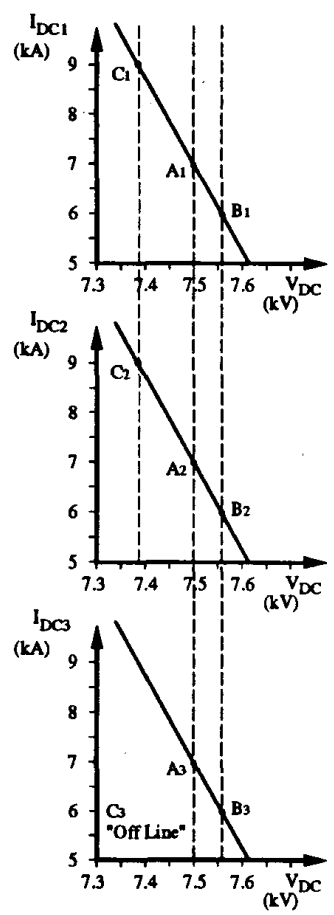

Fig. 2: Example of the dc Droop Scheme for the System of Figure 1

current level, and $V_{\text {est }}$ is an fictitious voltage source used to get the controlled characteristic to intersect the characteristic of the built- in droop at a selected point. Thus, $\alpha$ can be computed to make the rectifier appear to have a different, or even variable commutation drop.

$$
\begin{gathered}
V_{d e s}=V_{e s t}-R_{c} * I_{d c}-K_{\alpha} * I_{d c} \\
\cos (\alpha)=\frac{V_{d e s}+R_{C} * I_{d c}}{V_{d o}}
\end{gathered}
$$

\section{Inverter droop and load shedding}

The inverters can feed either passive loads or an ac system that must maintain synchronism with other parts of the system (there may be a parallel ac path). In either case, it is possible to adjust inverters to control both ac voltage and ac frequency (which in the case of a synchronously connected system should actually translate into a phase angle control, not frequency control). The frequency or phase signal of the inverters may be derived from a power or current setpoint established for the inverters. It is well known that most loads are sensitive to both voltage and frequency. It is possible to carry out the concept of droop one step further, and use the voltage at the dc side of the inverters as a signal to the inverter to adjust its ac-side load to some extent by adjusting either its voltage or its frequency (or phase angle), or a combination of the two. In this way, a certain measure of demand control is exercised automatically, precisely as is the case in an ordinary ac-only power system, but this time using the dc side voltage as a surrogate for the ac frequency signal. This slight demand control based on dc voltage helps stabilize the system: as the voltage increases due to a reduction in power demand somewhere in the system, not only do the rectifiers reduce their power output, but also the inverters increase theirs, and vice-versa.

In more extreme contingency and outage cases, simple inverter droop may not be sufficient to stabilize the system. In these cases it is possible to design specific inverter characteristics intended to produce selective load shedding. If the inverters adjust their phase based on a preset power order, a fall in dc mesh voltage level requires the inverters to increase their dc current in order to continue to supply constant power to their loads. This increase in current may cause the dc voltage to fall further, and can lead to system collapse.

This problem can be avoided by adding a voltage dependent current limit for the inverters. Figure 3 shows a typical inverter characteristic with the inverter regulating power for $V_{d c}>V_{D C \min }$ and then entering a VDCOL mode below this voltage. This limit is designed such that the current drawn by the inverter will reach zero at a set level.

This control results in the system reaching a new steady state where none of the inverters is able to reach its current or power setpoint, but it does keep the system in operation. This type of forced load shedding on the part of the inverters would allow the system to recover from the loss of a one or more generators or rectifiers without the need for total shut down. This feature of inverter operation provides an additional, albeit somewhat more drastic, droop characteristic to the system similar to underfrequency load shedding in ac systems. The set points of the inverters can be adjusted in an automated manner by a central control using communications, as is now the case with automatic generation control. A high priority load will have little loss in current as the dc voltage falls, while a low priority load could shut down after a small voltage sag.

\section{Rectifier limits}

The rectifier operates in an $\alpha_{\min }$ mode for much of its normal operating range. Large increases in current cause the rectifier to hit limits [13]. The rectifiers must be operated to have sufficient reserve capability, so that the loss of a single rectifier permits the uninterrupted operation of the system after the droop controls make the system settle into a new steady-state operating point.

In the examples below, the rectifier remains at $\alpha_{\min }$ until the rectifier current reaches 1.3 per unit. At this point it enters a mode where the slope of the droop characteristic changes. The slope is adjusted so that the 


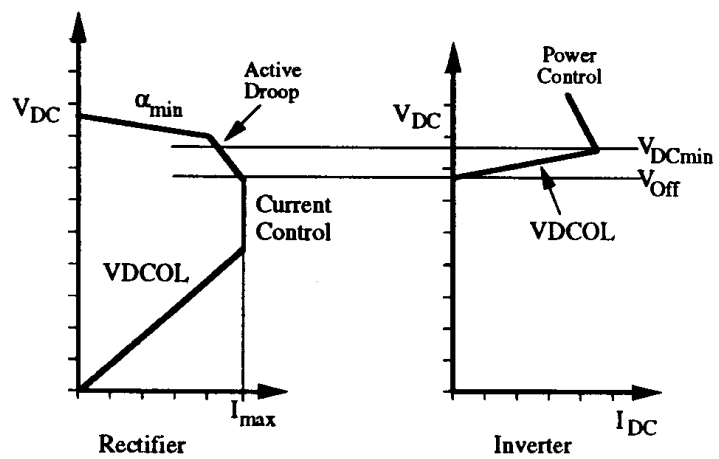

Fig. 3: Complete Rectifier Control Characteristic

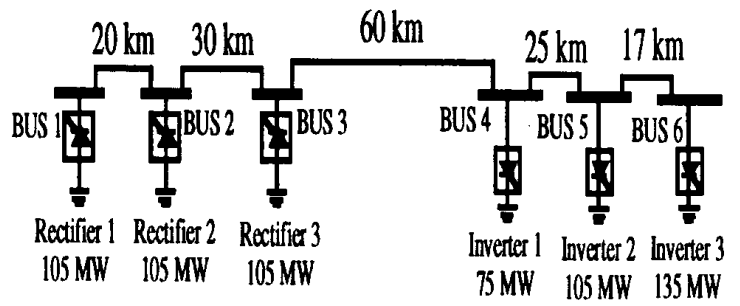

Fig. 4: Superconducting Point to Point System with Parallel Taps

dc voltage level falls to 0.85 per unit when the current reaches 1.6 per unit. The rectifier then enters a current control mode to maintain the current level at 1.6 per unit. The rectifier enters a voltage dependent current order limit (VDCOL) mode if the dc voltage level continues to fall. This allows the rectifier to starve the fault by increasing its firing angle to $90^{\circ}$. Figure 3 shows the complete control characteristic of the rectifier.

The boundaries where the rectifiers switch modes are consistent among all rectifiers. This scheme has no difficulties if there are slight errors between the transitions of different rectifiers, since there is always at least one rectifier in voltage control mode. If one converter changes modes, it changes the current sharing ratio between the other rectifiers, but the system remains stable. The inverters enters a voltage control mode when the rectifiers enter the controlled droop mode.

\section{STUDY SYSTEM RESULTS}

Assume a superconducting urban infeed based on a high current, low voltage dc line with parallel connected rectifier and inverter terminals. Figure 4 shows the configuration of such a system. The system is build around a $152 \mathrm{~km} \mathrm{dc}$ line, with parallel rectifier taps at $20 \mathrm{~km}$ and $50 \mathrm{~km}$. There are also two parallel inverter taps at $110 \mathrm{~km}$ and $135 \mathrm{~km}$. Table 1 provides details.

This system can be further expanded through the addition of parallel taps on the dc line. The converter

\begin{tabular}{|l|c|c|c|}
\hline Converter & $\begin{array}{c}\text { Power } \\
\text { Rating }\end{array}$ & $\begin{array}{c}\text { Current } \\
\text { Rating }\end{array}$ & $\begin{array}{c}\text { Firing } \\
\text { Angle }\end{array}$ \\
\hline Rectifier 1 & $105 \mathrm{MW}$ & $7 \mathrm{kA}$ & $\alpha=5^{\circ}$ \\
\hline Rectifier 2 & $105 \mathrm{MW}$ & $7 \mathrm{kA}$ & $\alpha=5^{\circ}$ \\
\hline Rectifier 3 & $105 \mathrm{MW}$ & $7 \mathrm{kA}$ & $\alpha=5^{\circ}$ \\
\hline Inverter 1 & $75 \mathrm{MW}$ & $5 \mathrm{kA}$ & $\gamma=25^{\circ}$ \\
\hline Inverter 2 & $105 \mathrm{MW}$ & $7 \mathrm{kA}$ & $\gamma=25^{\circ}$ \\
\hline Inverter 3 & $135 \mathrm{MW}$ & $9 \mathrm{kA}$ & $\gamma=25^{\circ}$ \\
\hline
\end{tabular}

Table 1: Converter Terminal Ratings for 6 Terminal dc System

settings need not be changed, although adding inverter terminals may tax the rectifier current limits.

\section{System model}

Each of the inverter terminals is assumed to be connected to an ac system represented by an infinite bus. The inverters are connected to an ideal three phase voltage source through a Y-Y transformer.

The line commutated CSI's are all represented by detailed models. The inverters operate in current control mode until the voltage falls below 0.95 per unit. They then enter a VDCOL mode, and shut down when the voltage reaches 0.85 per unit. The mesh is represented using lumped inductor models to represent the cables. There are no circuit breakers or other protective devices used on the dc system.

\section{Loss of a Rectifier Terminal}

The first case simulates rectifier 1 shutdown and restart. Upon initial startup all three rectifiers approach $7000 A$. The rectifier currents are shown in Figure 5(a). The inverter currents are shown in Figure 5(b). The voltage falls far enough to cause the inverters to enter their VDCOL modes, and fail to meet their current setpoints while rectifier 1 is off. Figure 5(c) shows the dc voltage levels. The plot shows both the actual dc voltage and the average voltage level. The voltage falls as the remaining recitifiers increase their currents to replace the inverter that shuts down.

\section{Inverter Startup Followed by dc Fault}

The next case looks at the startup of inverter 3 , followed by a resistive fault (with $R_{f}=0.1 \Omega$ ) near inverter 2 . This resistance shows a worst case operating point for the rectifiers. The fault voltage moves the rectifiers into their current limit control modes, but is high enough to keep them from entering their VDCOL modes. Figure $6(\mathrm{a})$ shows the rectifier currents. The first increase is due to the startup of the inverter. They later increase further, and settle into a new operating point. This is because the rectifiers are in the maximum current mode rather than the VDCOL. Figure 6(b) shows the inverter currents. The current for inverter 3 increases, and then all of the currents go to 


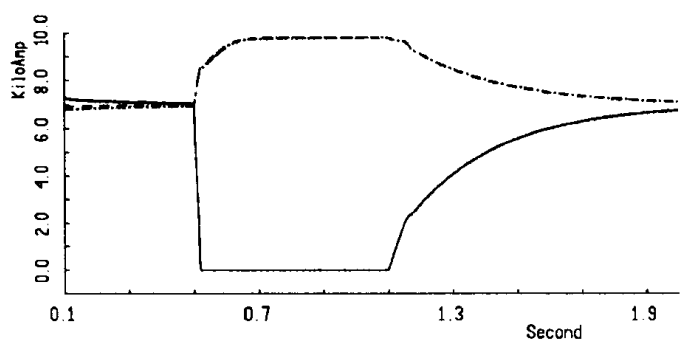

(a) Rectifier Currents

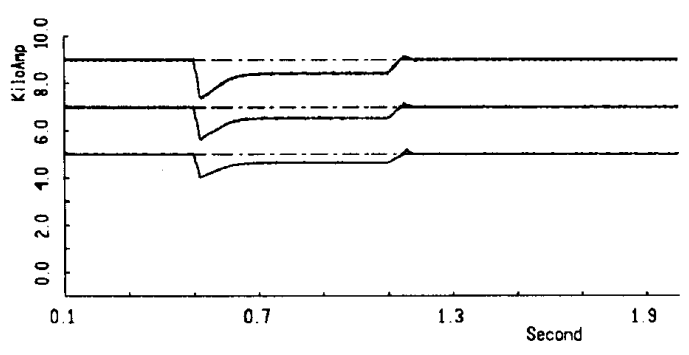

(b) Inverter Currents for Inverters 1, 2, and 3

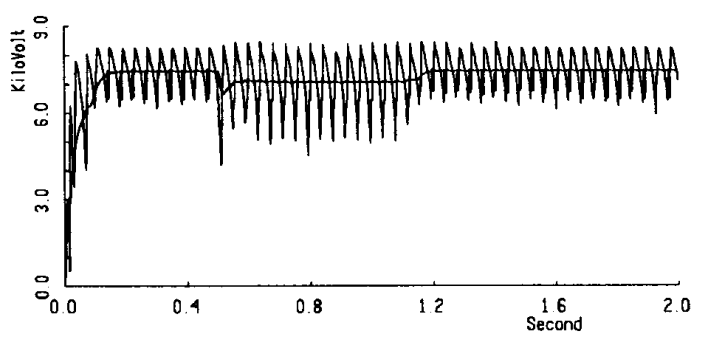

(c) DC Voltage at Rectifier Terminals

Fig. 5: Six Terminal Parallel Connected System Supplying Line Commutated CSI's. Case I: Rectifier 1 Shuts Down, Restarts After 0.6 Seconds

zero after the fault. Figure 6(c) shows the rectifier and inverter voltage levels. The voltage does not go to zero due to the presence of the fault resistance.

\section{UNRESOLVED ISSUES}

This paper has presented a concept. Many issues will require additional consideration before the actual use of this concept in practice. Issues that deserve further consideration include: study of the effect of commutation failures, reactive demand requirements at rectifiers for line-commutated inverters, implications of discrete tap changers and a more thorough consideration of the communication requirements. Our simulations and studies to date indicate that none of these issues is likely to result in an insurmountable problem.

It may be possible to extend the concept to systems that are not superconducting. This would complicate

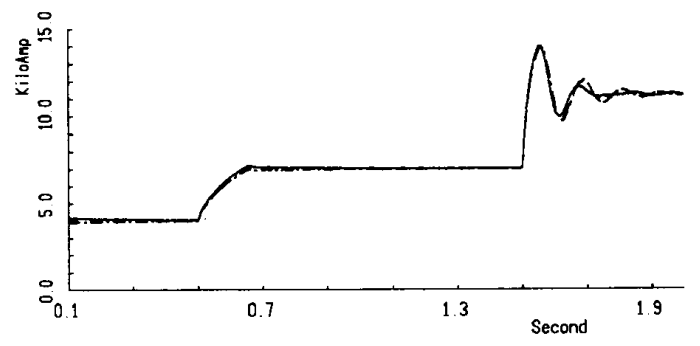

(a) Rectifier Currents

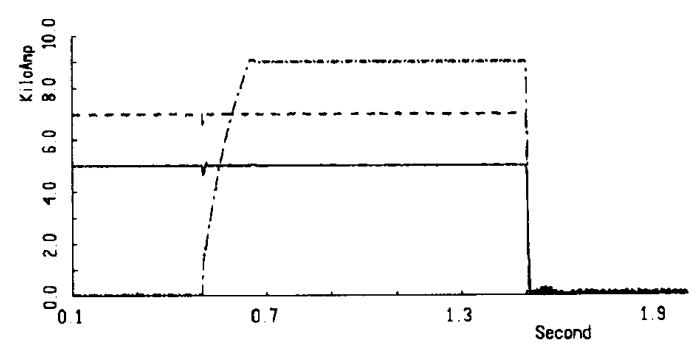

(b) Inverter Currents for Inverters 1, 2, and 3

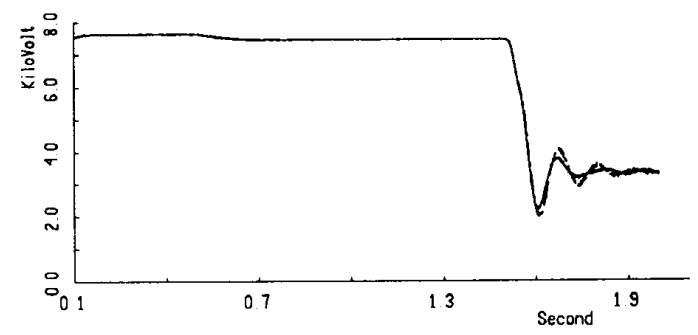

(c) DC Voltage at Rectifier Terminals

Fig. 6: Six Terminal Parallel Connected System Supplying Line Commutated CSI's. Case II: Start-up of Inverter 6, then Resistive Fault with $R_{f}=0.1 \Omega$

the controls: every terminal would have to infer the value of some voltage to regulate based on its local dc voltage and current information and a knowledge of the network components in service. The exploration and design of the droop concept in a lossy MTdc environment is beyond the scope of the present paper.

\section{CONCLUSION}

In conclusion, dc system voltage can provide communication-independent control capabilities to a dc system in much the same way as frequency does for an ac system. It can permit the regulation of rectifiers and inverters across systems, whether the systems to which the inverters are connected operate synchronously or not. Another advantage of voltage droop is that it makes it possible to operate a multi-rectifier and multiinverter meshed configuration that is readily expand- 
able. The use of voltage as a droop signal is most attractive for the superconducting case, but should also work reasonably well for the case of tightly connected dc systems with short dc lines.

\section{ACKNOWLEDGMENT}

This work was funded by NSF grant\#8818339 and EPRI Project RP7911-12.

\section{REFERENCES}

[1] L. K. Kirchmayer. Economic Operation of Power Systems. John Wiley \& Sons, Inc., New York, 1958. General Electric Series.

[2] N. Cohn. Control of Generation and Power Flow on Interconnected Poser Systems. John Wiley \& Sons, Inc., New York, 1961.

[3] A. J. Wood and B. F. Wollenberg. Power Generation, Operation, and Control. John Wiley \& Sons, Inc., New York, 1984.

[4] R.F. Giese, T.P. Sheahan, A.M. Wolsky, D.K. Sharma, "High-Temperature Superconductors: Their Potential For Utility Applications," IEEE Transactions on Enery Conversion. Vol. 7, No. 3, pp. 589-597, September 1992.

[5] J. Arrillaga, High Voltage Direct Current Transmission. Peter Peregrinus, Ltd., London, 1983.

[6] Final Report for EPRI Project RP-7911-12, in preparation.

[7] J. Reeve, "Multiterminal HVdc Power Systems," IEEE Trans. on Power Apparatus and Systems. Vol. 99, pp. 729-737, March/April 1980.

[8] R. Foerst, G. Heyner, K.W. Kanngiesser, and H. Waldmann, "Multiterminal Operation of HVdc Converter Stations," IEEE Trans. on Power Apparatus and Systems. Vol. 88, pp. 1042-1052, July 1969.

[9] K.W. Kanngiesser, J.P. Bowles, §. Ekström, J. Reeve, and E. Rumpf, "HVdc Multiterminal Systems," CIGRE, 14-08, 1974. (ELECTRA.) August, 1974.

[10] R. Jötten, J.P. Bowles, G. Liss, C.J.B. Martin, and E. Rumpf, "Control in HVdc Systems, The State of the Art, Part II: Multiterminal Systems," CIGRE 14-07 28th Session Paris, France, 1980.

[11] F. Nozari, C.E. Grund, and R.L. Hauth, "Current Order Coordination in Multiterminal dc Systems," IEEE Trans. on Power Apparatus and Systems. Vol. PAS100, pp. 4628-4635, November 1981.

[12] R.H. Lasseter, K.H. Krüeger, and D. Povh, "Control of Multiterminal dc Systems," MONTECH '86, Montreal, Canada, No. THO-154-5, pp. 120-125, 1986.

[13] J. Arrillaga, S. Sankar, N.R. Watson, and C.P. Arnold, "Operational Capacity of Generator-HVdc Converter Units," IEEE Trans. on Power Delivery. Vol. 6, pp. 1171-1176, July 1991.

Rambabu Adapa received his $\mathrm{Ph} . \mathrm{D}$ in electrical engineering from the University of Waterloo, Ontario, Canada in 1986. Dr.Adapa joined the Power System Planning and Operation program of the Electric Power
Research Institute (EPRI), Palo Alto, CA in June 1989. Prior to joining EPRI, he was Staff Engineer in the Systems Engineering Department of Mc-Graw Edison Power Systems, Franksville, Wisconsin.

Fernando L. Alvarado (SM'78) obtained a Ph.D. from the University of Michigan. He is currently a Professor at the University of Wisconsin in Madison in the Department of Electrical and Computer Engineering. His main interests are in computer applications to power systems and large scale problems.

Brian K. Johnson (S'86) received the Ph.D. in Electrical Engineering in 1992 from the University of Wisconsin-Madison. He is currently an Assistant Professor in the Department of Electrical Engineering at the University of Idaho. His interests include HVdc transmission, power systems, and power electronics.

Robert H. Lasseter (F'92) received the Ph.D. degree in physics at the University of Pennsylvania, Philadelphia, in 1971. He was a Consultant Engineer at General Electric Company until he joined the University of Wisconsin-Madison in 1980. His main interests are the application of power electronics to utility systems and simulation methods. 